\title{
Damping Properties of Aluminum/ Duralumin Multi-Layered Graded Structures Fabricated by Hot Rolling
}

\author{
Hideaki Tsukamoto \\ Department of Mechanical Engineering, Faculty of Science and Engineering, Hosei University, Tokyo, Japan
}

Email address:

htsukamoto@hosei.ac.jp

To cite this article:

Hideaki Tsukamoto, Damping Properties of Aluminum/ Duralumin Multi-Layered Graded Structures Fabricated by Hot Rolling. American Journal of Physical Chemistry. Vol. 6, No. 5, 2017, pp. 97-102. doi: 10.11648/j.ajpc.20170605.13

Received: March 13, 2017; Accepted: March 23, 2017; Published: November 28, 2017

\begin{abstract}
This study aims to fabricate aluminum (A1050)/ duralumin (A2017) multi-layered structures with interface composition gradient by hot rolling, and investigate their nanoindentation properties, and macro-mechanical property such as damping. 2- and 6-layered aluminum/ duralumin graded structures with asymmetric lay-ups from one side of aluminum to another side of duralumin have been fabricated, which suffer from three different heat-treatments such as (1) as-rolled (no heat-treatment), (2) annealed at $400^{\circ} \mathrm{C}$ and (3) homogenized at $500^{\circ} \mathrm{C}$ followed by water quenching and aging (T4 heat treatment). Nanoindentation demonstrated higher hardness and elastic modulus correspond to higher $\mathrm{Cu}$ content in annealed and aged samples. Duralumin in annealed samples shows much lower hardness and elastic modulus than those in as-rolled and aged ones. For damping properties, 2-layered graded structures show higher values than 6-layered graded structures, which are lower than single layers of aluminum.
\end{abstract}

Keywords: Multi-Layered Structures, Functionally Graded Materials (FGMs), Internal Friction, Nanoindentation

\section{Introduction}

Multi-layered structures surpass single layer structures in terms of various properties. Most multi-layered structures not only preserve the original characteristics of the individual layer metals but also provide additional functional properties [1]. Functional multi-layered and sandwich structures are being widely manufactured for increasing industrial needs. Generally, multi-layered structures are advantageous in their characteristics such as good thermal conductivity, anti-corrosion properties, wear resistance, surface quality, and so forth. Therefore, clad structures can be a good solution for products with multi-functional requirements in chemical industry, maritime industry, electric appliance industry and automobile industry [2].

Fabrication methods for multi-layered metal structures include explosion, forging, roll bonding, friction welding, or coaxial extrusion [3]. Among these approaches, the most economic and productive manufacturing process for large-sized flat clad metal sheets is considered to be roll bonding. Plural raw sheets are rolled together and bonded into a unified clad sheet. Roll bonding, as a solid phase welding method of bonding same or dissimilar metals by roll deformation at room temperature or elevated temperature, has been applied to fabricate laminated composites [4]. In roll bonding processes, layer sheets are bonded together by interface diffusion while the thickness is reduced. The roll bonding processes have many advantages, such as accurate dimension control, fine surface quality, and straight bonding layers. Aluminum-lithium alloy, compositionally equivalent to A8090, was roll clad to alloy A7072 under different rolling conditions, and its interface microstructure and bond shear strength studied [5]. Aeronautical grade aluminum alloys are normally roll clad by $\mathrm{Al}-1 \mathrm{wt} \% \mathrm{Zn}$ (alloy A7072) to improve resistance against atmospheric corrosion [6].

Nanoindentation has been receiving a great deal of attention as an invaluable technique for probing the mechanical behavior of materials at extremely small scales, which also have an ability to measure the properties of materials in thin films and coatings [7, 8]. This technique is well suited for the investigation of mechanical properties of multilayered structures. It is considered that nanoindentation technique is of considerable use for transient of mechanical properties at the interface in the multilayered structures. 
Damping is a significant dynamic parameter for noise and vibration control and impact resistance. Accurate information on damping of such structural materials has been recognized to be of crucial importance to suit operational needs in cyclic loading and vibration of structures. Damping is a kind of energy dissipation, which may be due to a combination of such mechanisms as visco-elastic behavior of each material, thermo-elastic damping due to cyclic heat flow, material damages etc. [9]. Damping in multi-layered structures involves a variety of energy dissipation mechanisms that depend on vibrational parameters such as frequency and amplitude and environmental conditions such as temperatures [10-14].

In this study, 2- and 6-layered aluminum/duralumin clad structures in asymmetric lay-up manners with one side of aluminum and another side of duralumin have been fabricated by hot rolling. The effect of heat treatments after hot rolling on nanoindentation properties such as elastic modulus and hardness, and internal friction of the multi-layered structures have been investigated.

\section{Experimental Procedures}

\subsection{Materials and Hot Rolling}

Aluminum (A1050) sheets and duralumin (A2017) sheets with a thickness of $1 \mathrm{~mm}$ were prepared for hot roll bonding. Duralumin contains 3 5 wt.\% Cu. Both sheets were heat-treated at $450^{\circ} \mathrm{C}$ for 2 hours, initially. These sheets were hot-rolled into layered structures with a reduction rate of $50 \%$ for 2 layers and $17 \%$ for 6 layers. The roll diameter and rolling speed are $100 \mathrm{~mm}$ and $12 \mathrm{~m}$. p. m., respectively. Before hot rolling, the aluminum and duralumin sheet surfaces were degreased by swabbing with acetone and drying in air, which were followed by scratching with brushing. The hot-rolled samples have a thickness of around $1 \mathrm{~mm} \pm 0.1 \mathrm{~mm}$. The hot rolling fabrication process is illustrated in Figure 1. Heat treatments for hot-rolled multi-layered structures produce three types of samples. The first samples are as-rolled ones (AR) (no heat treatment), the second samples are those annealed at $400^{\circ} \mathrm{C}$ followed by cooling in furnace (HT400), and the second samples are those homogenized at $500^{\circ} \mathrm{C}$ followed by water quenching and aging at room temperature (HT500) (T4 heat treatment). The sample descriptions of 2and 6-layered graded structures are shown in Table 1.

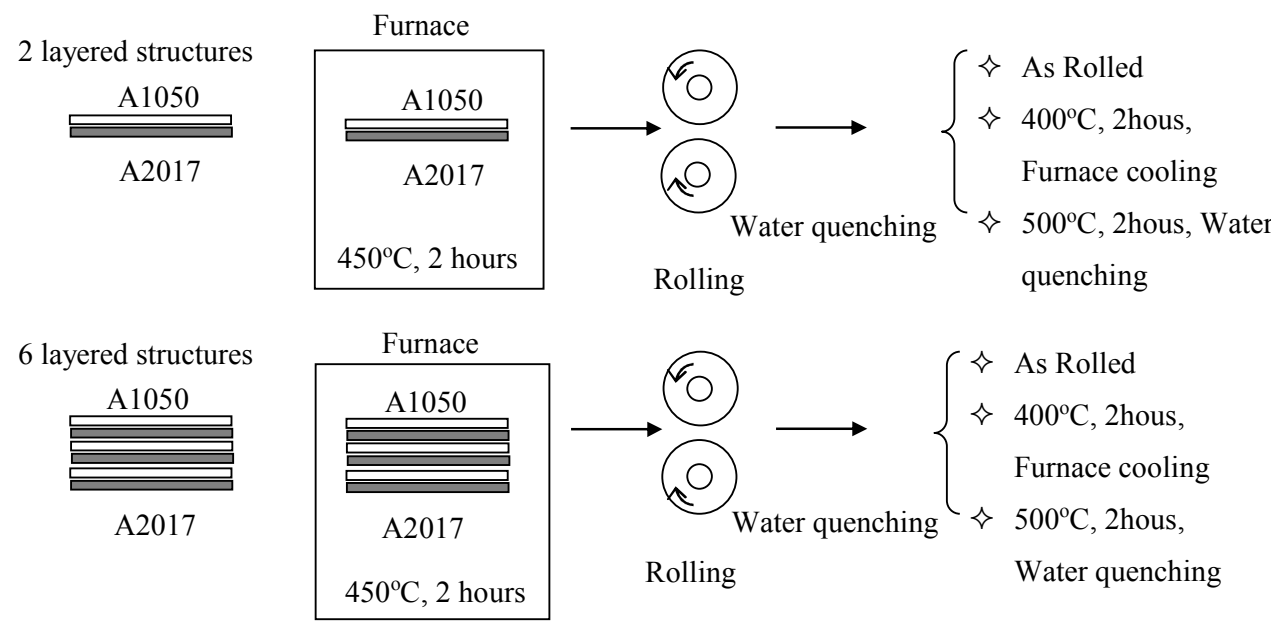

Figure 1. Hot rolling joining processes of 2-layered and 6-layered structures.

Table 1. Sample descriptions of aluminum/ duralumin 2-and 6-layered structures.

\begin{tabular}{ll}
\hline 2LAR & As-rolled (no heat treatment) 2-layered clad structures \\
2LHT400 & $400^{\circ} \mathrm{C}$ heat-treated 2-layered clad structures \\
2LHT400 & $500^{\circ} \mathrm{C}$ heat-treated 2-layered clad structures \\
6LAR & As-rolled (no heat treatment) 6-layered clad structures \\
6LHT400 & $400^{\circ} \mathrm{C}$ heat-treated 6-layered clad structures \\
6LHT500 & $500^{\circ} \mathrm{C}$ heat-treated 6-layered clad structures \\
\hline
\end{tabular}

\subsection{Characterization}

The samples for microscope observation and indentation tests were prepared by embedding the pieces cut from hot-rolled sheets into the resin. nanoindentation tests were conducted with a U9820A Agilent nano indenter G200 (Agilent Tech. Inc., USA), whose resolutions of the loading and displacement of the systems are $50 \mathrm{nN}$ and less than 0.01 $\mathrm{nm}$, respectively. A Berckovich diamond indenter was used. The thermal drift rate was less than $0.5 \mathrm{~nm} / \mathrm{s}$ during the measurements. A strain rate was set at $0.05 / \mathrm{s}$. The tests were performed at room temperature (RT).

The measurements of internal friction $\left(Q^{-1}\right)$ were carried out using a free-decay method of free-free flexural resonant vibration at room temperature in air. The set-up of internal friction measurements is depicted in Figure 2. The specimen for internal friction measurement has a size of $80 \mathrm{~mm}$ in length, $10 \mathrm{~mm}$ in width and $1 \mathrm{~mm}$ in thickness. A small piece of ferromagnetic Fe foil $(8 \mathrm{~mm} \times 4 \mathrm{~mm} \times 0.2 \mathrm{~mm})$ was attached to both ends of the specimen in order to excite mechanical vibrations efficiently by an electromagnetic force and to sensitively monitor the vibration by an induced current. The frequency varies depending on types of samples. For 2-layered samples the frequency was around $900 \mathrm{~Hz}$, while 
for 6-layered samples the frequency was around $1180 \mathrm{~Hz}$. After a steady-state vibration, the driving signal was turned off and the free-decay curve was recorded in a computer with a high-speed analogue-digital converter. The measurement was carried out for both cases in which one case is aluminum side is top and duralumin side is bottom, and another case is aluminum side is bottom and duralumin side is top.

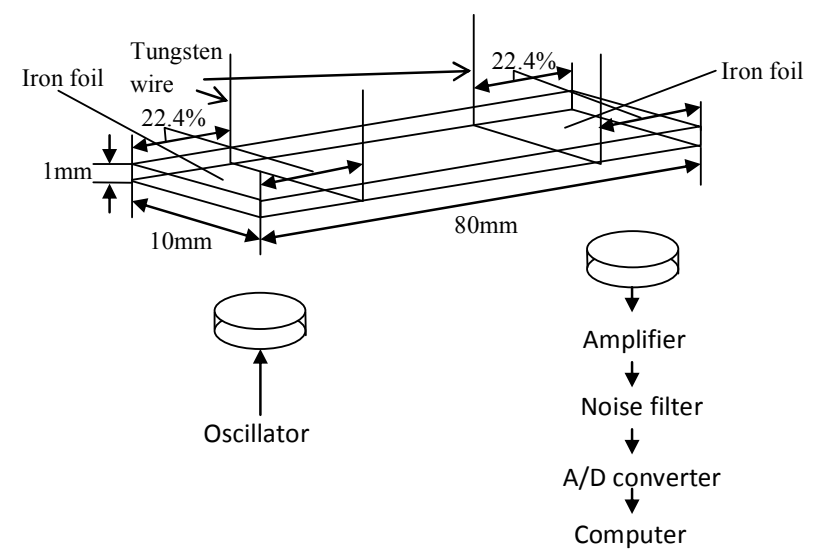

Figure 2. Set-up for measurement of internal friction.

\section{Experimental Results}

2-and 6-layered structures were soundly fabricated using hot-rolling methods. The OM images of the 2- and 6-layered aluminum/duralumin structures are shown in Figure 3. It is seen that as-rolled samples (2LAR and 6LAR) show clear boundaries between neighbor layers, while heat-treated samples (2LHT400, 2LHT500, 6LHT400 and 6LHT500) show unclear boundaries because heat treatments are considered to promote diffusion of $\mathrm{Cu}$, which is basically contained in duralumin. It can be considered that $\mathrm{Cu}$ content gradually varies from high level at the duralumin side to low level at the aluminum side in heat-treated samples, which means that heat treatments can make gradient distributions of $\mathrm{Cu}$ at the interface like functionally graded materials. Such a gradient can produce gradient distributions of various properties such as mechanical, thermal, electrical and other properties, which can be controlled by heat treatment procedures.

Nanoindentation properties of 2-layered structures are shown in Figure 4. The tendency in the nanoindentation hardness distribution is the same as that in micro-Vickers hardness distribution. Both A2017 and A1050 in 2LHT400 are much softer than those in others. 2LHT500 shows extremely high hardness in A2017. For nanoindentation elastic modulus of 2-layered clad structures, 2LHT500 shows high values in both A1050 and A2017. Difference in elastic modulus between A1050 and A2017 are relatively small in any heat-treated samples, while difference in elastic modulus among the samples suffering different heat treatments are obvious, in which $500^{\circ} \mathrm{C}$ heat-treatment (HT500) contributes to increase of elastic modulus of both A1050 and A2017. Figure 5 shows the nanoindentation elastic modulus and hardness in 6-layered structures. The tendency is the similar to that in 2-layered structures shown in Figure 4. It can be found that difference in elastic modulus between A1050 and A2017 in 6-layered structures is slightly large compared to that in 2-layered structures. (a)

(c)
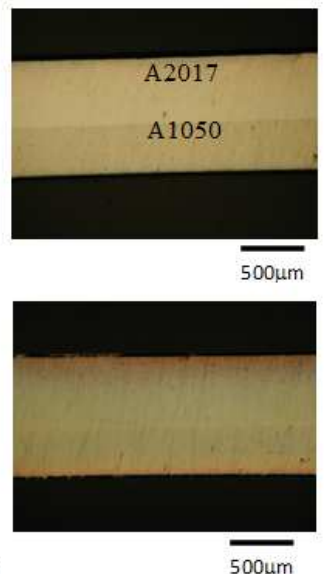

(e)

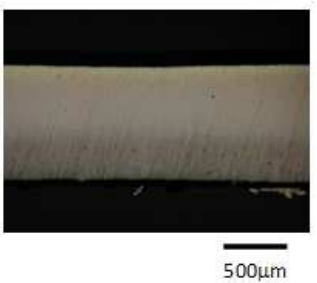

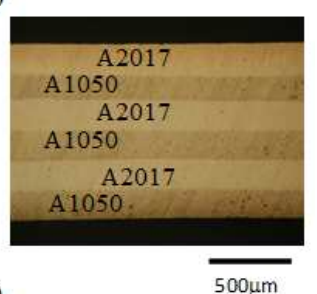

(d)

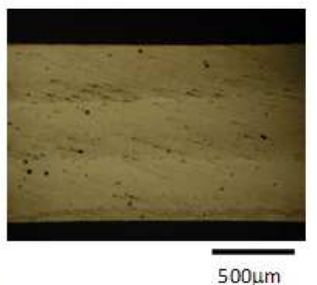

(f)

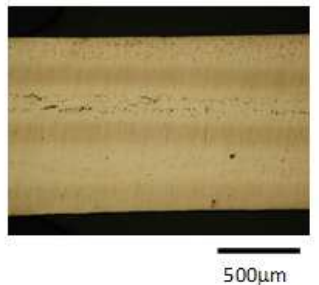

Figure 3. OM images of 2- and 6-layered structures, (a) 2LAR, (b) 6LAR, (c) 2LHT400, (d) 6LHT400, (e) 2LHT400, (f) 6LHT500. (a)

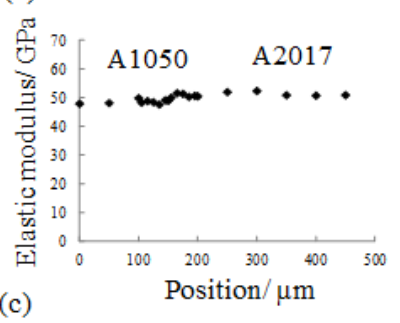

(c)

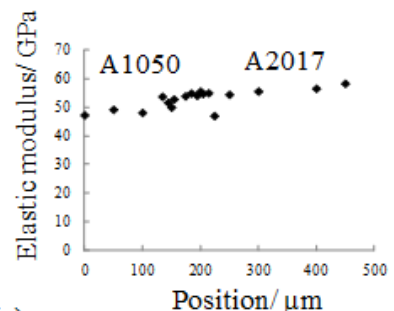

(e)

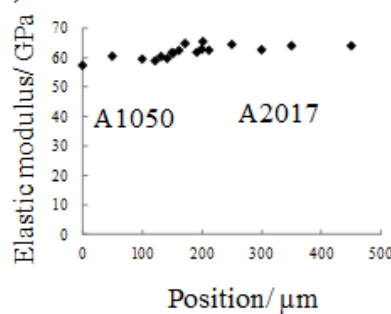

(b)

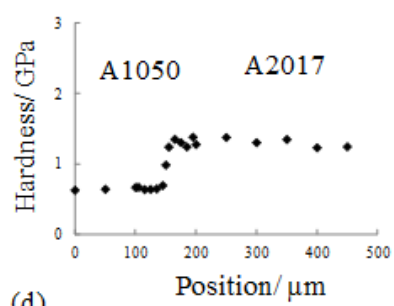

(d)

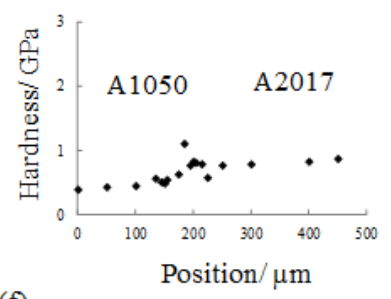

(f)

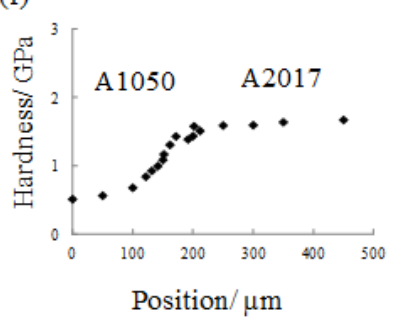

Figure 4. Nanoindentation elastic modulus ((a), (c) and (e)) and hardness ((b), (d) and (f)) of 2-layered structures. (a), (b) 2LAR, (c), (d) 2LHT 400, (e), (f) 2 LHT 500 . 
(a)

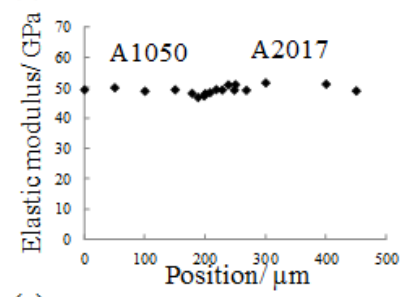

(c) (b)

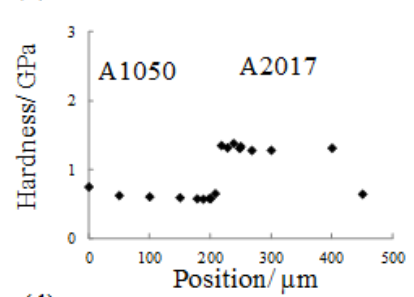

(d)
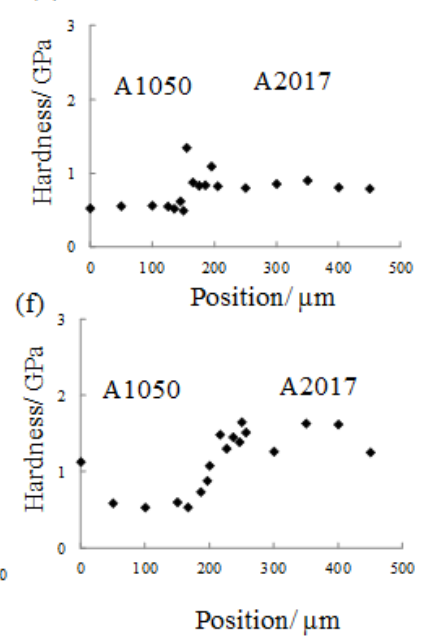

Figure 5. Nanoindentation elastic modulus ((a), (c) and (e)) and hardness ((b), (d) and (f)) of 6-layered structures. (a), (b) 6LAR, (c), (d) 6L HT 400, (e), (f) $6 L$ HT 400 .

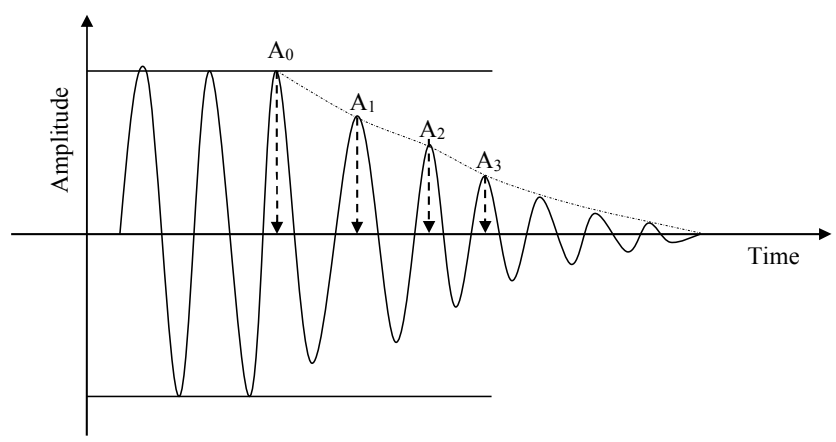

Figure 6. Schematic illustration of free vibration decay.

Next let's look at the internal friction results. Figure 6 shows the schematic illustration of the obtained results with a typical free vibration decay. $A_{n}$ is the amplitude measured for $\mathrm{n}$ cycles apart from the wave the resonance vibration intentionally stopped, which is given as,

$$
A_{n}=A_{0} \exp (-n \pi \delta)
$$

Here, $\mathrm{A}_{0}$ is the amplitude of the vibration wave on intentional vibration stopped, $\delta$ is the legalistic decrement. Internal friction, $\mathrm{Q}^{-1}$, is also related to $\delta$, which is expressed by

$$
Q^{-1}=\delta / \pi=\Delta W / W=\left(A_{n}^{2}-A_{n+1}^{2}\right) / A_{n}^{2}
$$

Here, $A_{n+1}$ is the amplitude of the $(\mathrm{n}+1)$-th vibration wave after the resonance vibration stopped, $\Delta W$ is the loss of vibration energy in one cycle during the n-th and $(n+1)$-th vibrations, and $W$ is the vibration energy in one cycle during the $n$-th and $(\mathrm{n}+1)$-th vibrations.

Figure 7 shows the internal friction, $Q^{-1}$, for uni-, 2- and 6-layered structures. This figure includes the data for $Q^{-1}$ measured with both A1050 side top and A2017 side bottom, and the inverse case in the samples. The data for measurements with both $\mathrm{n}=100$ and 500, which are the number of waves of vibration from the start of decay, are shown. It is seen that there is not so much difference between the case that A1050 side is top and A2017 side is bottom, and the inverse case. It is also seen that 1050 uni-layer structures show highest $Q^{-1}$ values. It can be seen that $Q^{-1}$ values for 2-layered structures are just between the $Q^{-1}$ values for A1050 uni-layer structures and A2017 uni-layer structures. Meanwhile, $Q^{-1}$ values for 6-layered structures are considerably low, which are lower than $Q^{-1}$ values for A2017 uni-layer structures. This result may be attributed to the asymmetric stacking of laminae in multi-layered structures tested. There is not so much difference among the different heat-treated samples, even though mechanical properties of A2017 is highly affected by heat treatments.

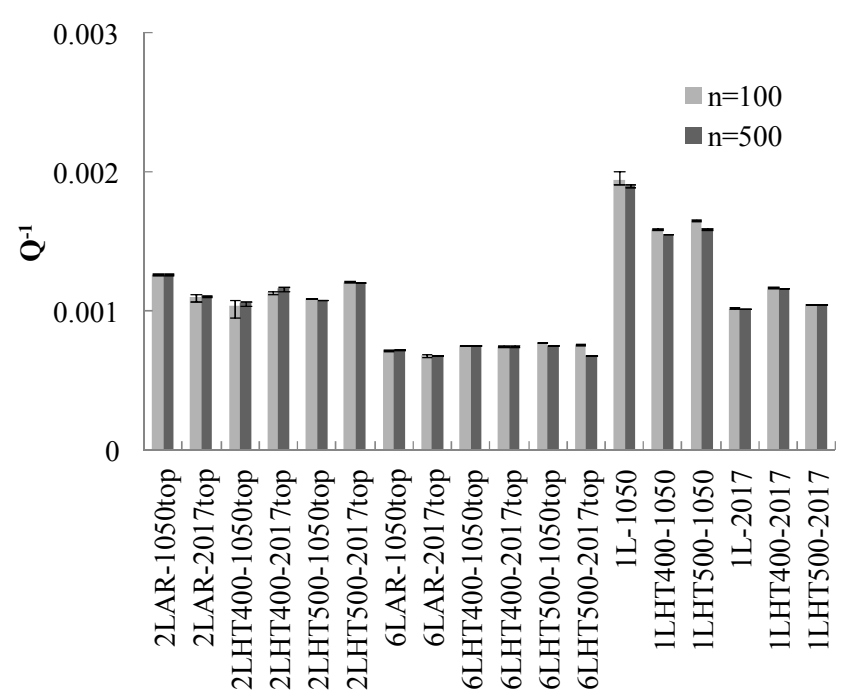

Figure 7. Internal friction, $Q^{-1}$, of multi-layered (uni-layered, 2-layered and 6-layered) structures.

\section{Discussion}

2-and 6-layered structures were successfully fabricated using hot-rolling method. For aluminum (A1050)/ duralumin (A2017) multi-layered structures, heat treatments largely affect the mechanical properties of A1050 and A2017, and $\mathrm{Cu}$ concentration around the interface. $\mathrm{Cu}$ distributions are related to nano- and micro-scale mechanical property distributions around the interface. In this study, using nanoindentation, elastic modulus and hardness were investigated, which varies to $\mathrm{Cu}$ concentration around the interface. Higher $\mathrm{Cu}$ concentration corresponds to higher hardness because $\mathrm{Cu}$ can produce intermetallics by reacting with $\mathrm{Al}$ during the aging processes, which leads to strengthening the materials with 
dispersed intermetallic precipitations. nanoindentation elastic modulus is also considered to be affected by nano- and micro-scale microstructure and $\mathrm{Cu}-\mathrm{Al}$ intermetallics, so these properties can be controlled by heat treatments.

For damping properties, 2-layered structures exhibit higher values than 6-layered structures. There have been many researches investigating the internal friction of layered samples theoretically and experimentally $[15,16]$. Generally, the number of layers in multi-layered structures has some effect on free vibration behavior [16]. In this study, there is not so much difference between the case that A1050 side is top and A2017 side is bottom, and the inverse case. Aluminium (A1050) uni-layered structures show the highest $Q^{-1}$ values. $Q^{-1}$ values for 2-layered structures are just between $Q^{-1}$ values for A1050 uni-layered structures and A2017 uni-layered structures. Meanwhile, $Q^{-1}$ values for 6-layered structures are considerably low, which are lower than $Q^{-1}$ values for A2017 uni-layered structures. This result may be attributed to the asymmetric stacking of laminae. It is considered that stress distribution in 2-layered samples are more biased than that in 6-layerd samples, which possibly affect the internal friction of the layered structures. The data that internal friction of the 6-layered is so small compared to others will need to take more examination based on some theoretical work.

It is also seen that there is not so much difference in internal friction among the different heat-treated samples, even A2017 samples. As seen in Figures 4 and 5, heat treatments largely affect nano- and micro-indentation properties of duralumin and aluminum/ duralumin interface. Hardness is considered to be related to inelastic deformation influenced by dislocation densities and movements. In the current damping measurement, flexure is very small, which is in the range of visco-elasticity, not plasticity. Therefore, even though dislocation densities and conditions and amount of precipitations in the samples with A2017 layers are affected by heart treatments, the influence of heat treatments on internal friction is not so large compared to the influence of the number of layers. It was reported in previous work that internal friction, $Q^{-1}$, of aluminium is around $0.64 \times 10^{-3}$, and that of duralumin is around $0.005-0.03 \times 10^{-3}$ [17]. The data obtained in the current study is reasonable, and it is considered that the results of the study is meaningful for design of such multi-layered structures.

\section{Conclusions}

2-and 6-layered aluminum (A1050)/ duralumin (A2017) structures were soundly fabricated using hot rolling methods. The effect of heat treatments on nano- and macro- mechanical properties was investigated. The findings in the study are summarized below.

(1) Boundaries between layers with different materials (aluminum and duralumin) are clearly seen in as-rolled (AR) samples, while heat-treated samples (HT400 and HT500) show unclear boundaries, which imply that diffusion of $\mathrm{Cu}$ occurs at the boundaries during heat treatment processes.
(2) Both elastic modulus and hardness are affected by heat treatments, particularly, in 6-layered structure samples. 2-layered structures show higher internal friction than 6-layered clad structures. Higher nanoindentation hardness and elastic modulus correspond to higher $\mathrm{Cu}$ content in $400^{\circ} \mathrm{C}$ and $500^{\circ} \mathrm{C}$ heat-treated samples. $400^{\circ} \mathrm{C}$ heat-treatments (HT400) make the samples softer, while $500^{\circ} \mathrm{C}$ heat-treatments (including water quenching and aging) (HT500) make duralumin much harder.

(3) No apparent difference can be seen in internal friction between the case that aluminum side is top and duralumin side is bottom and the inverse case. Aluminium uni-layer structures indicate the highest internal friction. Internal friction for 2-layered structures are between those for aluminum uni-layer structures and duralumin uni-layer structures. Internal friction for 6-layered structures are considerably low, which are lower than that for duralumin uni-layer structures. Internal friction is not so much affected by heat treatments in any samples, even the samples have A2017 layers.

\section{References}

[1] J. E. Lee, D. H. Bae and W. S. Chung, "Effects of annealing on the mechanical and interface properties of stainless steel/aluminum /copper clad-metal sheets," J Mater Process Technol, 2007, vol. 187-188, pp. 546-549.

[2] Y. M. Hwang, H. H. Hsu and Y. L. Hwang, "Analytical and Experimental Study on Bonding Behaviour at the Roll Gap During Complex Rolling of Sandwich Sheets," Int. J. Mech. Science, 2000, vol. 42, pp. 2417-2437.

[3] X. P. Zhang, T. H. Yang, J. Q. Liu, X. F. Luo and J. T. Wang, "Mechanical properties of an $\mathrm{Al} / \mathrm{Mg} / \mathrm{Al}$ trilaminated composite fabricated by hot rolling," J Mater Sci, 2010, vol. 45, pp. 3457-3464.

[4] L. Chen, B. Jha, Z. Yang, G. G. Xia, J. W. Stevenson and P. Singh, "Clad Metals by Roll Bonding for SOFC Interconnects," J Mater Eng Perform, 2006, vol. 15, pp. 399-403.

[5] P. Mallesham, A. A. Gokhale and A. Dutta, "Interface microstructure and bond shear strength of aluminum alloy AA8090/AA7072 roll clad sheets," J Mater Sci Lett, 2003, vol. 22, pp. 1793-1795.

[6] I. J. Polmear, "Light Alloys, The Metallurgy of the Light Metals," 3 rd ed. (Arnold Publishers, London, 1995) vol. 331, pp. 77.

[7] M. Fujikane, D. Setoyama and S. Nagao, "Nanoindentation examination of yttria stabilized zirconia (YSZ) crystal," J Alloy Compound, 2007, vol. 431, pp. 250-255.

[8] F. Gao, T. Takemoto, "Mechanical properties evolution of Sn-3.5Ag based lead-free solders bynanoindentation," Materials Letters, 2006, vol. 60, pp. 2315-2318.

[9] R. Gibson, "Damping characteristics of composite materials and structures," J. Materials Engineering and Performance, 1992, vol. 1, pp. 11-20. 
[10] A. L. Araújo, P. Martins, C. M. Mota Soares, C. A. Mota Soares, J. Herskovits, "Damping optimization of viscoelastic laminated sandwich composite structures," Structural and Multidisciplinary Optimization, 2009, vol. 39, pp. 569-579.

[11] Z. Li, Y. L. Jia, N. Tang, M. Fang, N. Liu, "A novel laminate combined with elasticity and damping," Journal of Materials Processing Technology, 2007, vol. 182, pp. 1-5.

[12] D. J. Lee, D-H. Ahn, E. Y. Yoon, S. I. Hong, S. Lee and H. S. Kim, "Estimating interface bonding strength in clad metals using digital image correlation," Scripta Materialia, 2013, vol. 68, pp. 893-896.

[13] M. Kameyama, M. Arai, "Optimal design of symmetrically laminated plates for damping characteristics using lamination parameters," Composite Structures, 2015, vol. 132, pp. 885-897.
[14] G. Demeshkin, M. E. Kozeko, V. M. Kornev, and V. D. Kurguzov, "Damping characteristics of composite structural materials fabricated by winding," Journal of Applied Mechanics and Technical Physics, 2001, vol. 42, pp. 169-173.

[15] P. Cupial and J. Niziol, "Vibration and damping analysis of a three-layered composite plate with a viscoelastic mid-layer," J. Sound Vibration, 1995, vol. 183, pp. 99-114.

[16] J. Gao and Y. Shen, "Vibration and damping analysis of a composite plate with active and passive damping layer," Applied Math Mech, 1999, vol. 20, pp. 1075-1086.

[17] J. Zhang, R. J. Perez, E. J. Lavernia, "Documentation of damping capacity of metallic, ceramic and metal-matrix composite materials," J Mater Sci, 1993, vol. 28, pp. 2395-2404. 